\title{
International Journal of Economics and Finance
}

www.ccsenet.org/journal.html

\section{The Relationship between Earnings and Stock Returns: Empirical Evidence from the Greek Capital Market}

\author{
Panagiotis E. Dimitropoulos \\ Teaching \& Research Associate \\ University of Peloponnese \\ Department of Sport Management
}

3-5 Lysandrou Str, P.C.23100, Sparta, Greece

Tel: 30-273-102-4096, 30- 693-689-8306

E-mail: dimitrop@uop.gr

Dimitrios Asteriou

Associate Professor

Hellenic Open University

City University, London

School of Social Sciences

Riga Feraiou 162 \& Tsamadou

Patras, Greece

Tel: 44-694-710-0540

E-mail: D.A.Asteriou@city.ac.uk

\begin{abstract}
The relationship between earnings figures and stock returns has been a topic of international research since decades. The purpose of this paper is to investigate the above relationship in the context of the Greek capital market. Previous studies resulted in controversial results regarding the usefulness of models which were using earnings levels or earnings changes as the explanatory variable. In an introductory context, this study examines the earnings-return relation applying four models, proposed by Kothari and Zimmerman (Journal of Accounting and Economics, 20, 155-192, 1995), on individual Greek stocks as well as portfolios between 1994-2004. The overall results, demonstrated a significant value relevancy of accounting earnings prepared under the Greek GAAP. Specifically in the Greek stock market the price model produces less biased ERC's than the return model but suffers from various econometric problems. Also, the use of cross-sectional and time-series aggregated data results in a large increase in the explanatory power of earnings for returns (for the return and differenced model) yielding more significant Earnings Response Coefficients.
\end{abstract}

Keywords: Earnings response coefficients, Stock returns, Price and returns models, Earnings relevance, Greece

JEL classification: M41, G10

\section{Introduction}

The relation between stock returns and accounting earnings has been an internationally popular subject of research for more than thirty years. Since Ball and Brown (1968) first documented the aforementioned relation, an extensive number of accounting literature has been published, all trying to best accommodate the incentives of the returns-earnings association, as well as the ability to forecast future earnings from stock movements and vice-versa.

Of course the interest for this subject is more than intense since accounting numbers are published in order to assist investors to take rationale investing decisions. Beaver (1989) mentioned that earnings per share is the only figure in the financial statements that receives the greatest attention by the investors. Moreover, earning numbers are supposed to facilitate analysts and investors to forecast future cash flows and deal with relative investments risks. For the above reasons there have been many studies in US, Europe and Far East trying to evaluate the possibility of achieving this 
objective. If we manage to enlighten the causes that drive the return-earnings relation then we will have accomplished a great step into creating a less risky decision-making environment.

The aim of this paper is to assess the association between published accounting earnings and stock returns, in the context of the Hellenic Capital Market. The disclosure legislation, as well as the accounting practises in Greece are different compared to US, UK and other Western countries but they have some similarities to other countries such as France, Italy, the Baltic region, Cyprus and Czech Republic. Despite the fact that the aforementioned issue has received great attention from researchers, the majority of studies on this field have focused on well developed capital markets creating a gap on the literature of less developed and organized stock markets. The Greek accounting setting can be characterized by moderate tax and financial accounting conformity, moderate use of accruals, low importance of the capital market and weak corporate governance. Therefore, the present study adds to the existing literature by examining the issue of earnings relevance within the context of an emerging capital market like Greece.

Under this framework we examined different return-earnings model specifications (Price, Return, Differenced and Deflated models) following Kothari and Zimmerman (1995). Annual data from companies that have their titles listed on the Athens Stock Exchange over an 11 year period (1994-2004), were used. Results indicate a significant value relevancy of accounting numbers in explaining stock returns under the Price and Return model specifications. The differenced and deflated models did not yield any significant results supporting the results from the two previous specifications.

Additionally, the cross-sectional and time-series aggregated procedures (see Dumontier and Labelle, 1998) resulted in a large increase in the explanatory power of earnings for returns (for the return and differenced model) yielding more significant earnings response coefficients (Hereafter ERC's).

The paper is organized as follows. The next section presents the review of relative literature that examined the existence of the return-earnings relation in the past, alongside with the empirical results that proved the above fact. Section 3 describes the data selection procedure and provides details on the methodological framework of the paper. Section 4 illustrates the empirical results from annual, cross-sectional and aggregated data and finally the last section is dedicated to concluding remarks, limitations and fruitful ways for future research.

\section{Literature review}

Several papers examined the ability of price and return models (along with some alternative forms) to accommodate the return-earnings relation. Gonedes and Dopuch (1974) declared that price models are conceptually inferior to return models under the presence of under-developed theories of valuation. Additionally Christie (1987) argues that price models present more econometric problems than return models. On the contrary there is a majority of studies that declare the superiority of the price model on explaining the return-earnings relation such as Bowen (1981), Olsen (1985), Landsman (1986), Barth et.al (1990, 1992) Barth (1991) and Harris et.al (1994). Furthermore, Kothari and Zimmerman (1995) documented that the earnings response coefficients are less biased and more economically sensible in the price model compared to the return and differenced models. On the other hand, price and differenced models suffer from heteroscedasticity and other specification problems relative to return model.

Consistent to Kothari and Zimmerman (1995) were the results by Martikainen et.al (1997) and Dumontier and Labelle (1998) in Finland and France respectively. The first used two different measures of the earnings variable, the published earnings numbers and the adjusted earnings numbers, estimated according to the recommendations by the Finnish Committee for Corporate Analysis (COC). They concluded that the return model specification (using the published accounting data) yields higher and more significant ERC's compared to differenced model specification under the adjusted accounting data. Dumontier and Labelle (1998) reached in the same conclusion regarding the ability of the return model to evaluate the return-earnings relation by providing highly significant ERC's. Also their tests indicated that a cross-sectional data cumulating procedure could yield a large increase in the explanatory power of the return model and the significance of the earnings response coefficient.

On the contrary, Vafeas et.al (1998) found conflicting evidence for the evaluating ability of the return model in the Cyprus stock market. They concluded that both specifications are important in explaining stock returns but the differenced model yield higher ERC's compared to the return model. This finding agrees with studies by Martikainen et.al (1991), Board and Day (1989), Alford et.al (1993) and Harris et.al (1994).

Finally, Pritchard (2002) examined the return-earnings relation in the countries of the Baltic region (Estonia, Latvia, and Lithuania). She documented a substantial difference in the association of the above variables. Lithuania showed the weakest and Estonia the highest value relevance followed by Latvia. In total the return model proved to perform better compared to differenced model specification.

As a conclusion we can say that we have conflicting results regarding the valuation ability of different model specifications. There is a group of studies that favours for the price model's ability to explain the return-earnings relation and another group which argues that return model performs better. Nevertheless all model specifications 
present serious econometric problems and they must be used with caution. As Kothari and Zimmerman (1995) argue, the use of all model specifications has the potential to provide more convincing and reliable evidence instead of considering each model separately.

\section{Data selection and methodology}

\subsection{Sample selection}

Our sample consists of 105 companies, all listed in the Athens Stock Exchange, with full annual data of reported earnings and stock prices during the period 1994-2004. Data were collected from the Athens Stock Exchange database. The initial sample contained 112 companies with full data for the period under investigation but we restricted it to companies with December fiscal year-end limiting the final number to 105 . The inclusion of the same 105 firms in the sample was imposed by the time-aggregation procedure which requires the variables for each firm to be available for each year under investigation. According to Collins et.al (1994) this fact is likely to bias the results, but since the influence of this bias on the final results is hard to be determined a priori, it is supposed to be insignificant.

We use per share values of earnings and returns in order to reduce heteroscedasticity on the error terms (see also Barth et.al, 1992; Kothari and Zimmerman, 1995). The earnings variable is annual earnings per share $\left(\mathrm{EPS}_{t}\right)$ for the price model, annual earnings per share deflated by the price at the beginning of the year $\left(\mathrm{EPS}_{\mathrm{t}} / \mathrm{P}_{\mathrm{t}-1}\right)$ for the return model and change in earnings per share $\left(\triangle \mathrm{EPS}_{\mathrm{t}}\right)$ for the differenced model.

The price and return variable is $\mathrm{P}_{\mathrm{t}}$ (Price model), $\mathrm{P}_{\mathrm{t}} / \mathrm{P}_{\mathrm{t}-1}$ (Return model) and $\Delta \mathrm{P}_{\mathrm{t}}$ (Differenced model). Annual stock returns, exclusive of dividends, are used and the earnings and price data are adjusted for stock splits, stock dividends, stock issues and the fact of currency translation (drachma to euro). No further trimming of the sample was conducted since we did not want to lose observations and affect the final results.

Table 1 illustrates the descriptive statistics of the price and earnings variables for all the years under investigation. As we can see the mean of all variables is higher than the median which indicates that data are skewed to the right side of the distribution. Also the mean is below the standard deviation for all the variables and the minimum and maximum values indicate a wide range of observations in the sample. Finally the mean EPS is 37 cents while the mean stock price is 6.3 euros providing a mean stock return of up to 11 per cent for the whole period of investigation. Also the mean value of EPS is decreasing from 1994 to 2002 but on the other hand mean stock prices increase and reach their peak in 1999 (annual descriptive statistics are not presented here- they can be provided upon request).

\section{INSERT TABLE 1 HERE}

\subsection{Methodological framework}

\subsubsection{Earnings and Return specification}

The rationale for the economic interpretation of return-earnings relation originates from a fixed valuation model in which stock prices are the discounted present values of future net cash flows (Kothari and Zimmerman, 1995; Watts and Zimmerman, 1986; Kormendi and Lipe, 1987; Ohlson, 1991). Since the expectations for the market's future cash flows cannot be measured, we use current earnings as an approximation for the market's expectation in our valuation models.

These models assume that the ex-dividend stock price at the end of a time period $t$ is a function of the published accounting earnings for the same period. There are four model specifications that we will use in our analysis, which all of them produce equal earnings response coefficients of $1 / \mathrm{r}$, where $r$ is the firm's expected rate of return (Kothari and Zimmerman, 1995).

$$
\begin{aligned}
& \text { Price Model: } \mathbf{P}_{t}=\mathbf{a}+\mathbf{b X _ { t }}+\mathbf{e}_{t} \\
& \text { Return model: } \mathbf{P}_{t} / \mathbf{P}_{t-1}=\mathbf{a}+\mathbf{b X} \mathbf{X}_{t} / \mathbf{P}_{\mathrm{t}-1}+\mathbf{e}_{\mathrm{t}} \\
& \text { Differenced Model: } \Delta \mathbf{P}_{\mathrm{t}} / \mathbf{P}_{\mathrm{t}-1}=\mathbf{a}+\mathbf{b X} \mathbf{X}_{t} / \mathbf{P}_{\mathrm{t}-1}+\mathbf{e}_{t} \\
& \text { Deflated Model: } P_{t} / \mathbf{E P S}_{t}=\mathbf{a} 1 / \mathbf{X}_{t}+b+e_{t}
\end{aligned}
$$

Where $P_{t}$ is the ex-dividend price at the end of the fiscal year $t$ and $X_{t}$ is earnings per share excluding taxes and discontinued operations for period $t, a$ and $b$ are the intercept and the earnings response coefficient respectively and $\mathrm{e}$ is the error term. Two important assumptions are made in order to evaluate these models, earnings follow a random walk and prices do not lead earnings (prices are set by the market only using the current and past time series of earnings).

The differenced (changes) model is used because we can produce a stationary series by differencing the price and earnings variables, so the econometric problems that appear in the estimation of the price model could be mitigated by taking the first differences (Christie, 1987). Additionally, the deflated specification was used in order to reduce the heteroscedasticity of the error terms and the cross-sectional variation of the slope coefficient (which is assumed to be constant). So we estimated the price model using earnings per share as the deflator where $b$ is the estimated ERC. 
Finally, the above four models were estimated for each year separately and as a pooled sample as well. Also, in order to take into consideration the 1999-2000 stock market crash, we divided our sample into two sub periods 1994-1998 and 1999-2004 in order to examine the relation of returns and earnings before and after the market's crash.

\subsubsection{Cross-sectional and time aggregated data}

There are several studies that divide reported earnings into two basic components, the value relevant component and the price irrelevant component. The first includes the information needed to explain stock prices movements, while the second is irrelevant in explaining stock returns (see also Beaver et.al, 1980; Lev, 1989; Ramakrishnan and Thomas, 1998; Dumontier and Labelle, 1998). Under this framework the cross-sectional aggregation of the firms could reduce the variance of the irrelevant component compared to the value relevant component and improve the overall results. Consequently all four models were re-estimated using a portfolio aggregation procedure. Stocks in each year were clustered into 15 portfolios where each portfolio included 7 stocks. The intuition behind this refinement is that investors are supposed not to be influenced by the variability in reported earnings, thus returns will be uncorrelated with the measurement error in earnings variables.

Beyond the value irrelevant noise in earnings that can affect the returns-earnings relation, we must consider the fact that earnings events are not recognized as fast as stock price events. This often delays the incorporation of important events into the financial statements thus current earnings do not capture all the important economic events (see also Basu, 1997; Raonic et.al, 2004). As a result the low value relevancy (as measured by the ERC and the coefficient of determination) of the price and return models could be attributed to the timeliness of earnings recognition. If this situation actually exists, we can improve the return-earnings relation by aggregating earnings and returns over long time periods, thus the longer the time horizon the higher the recognition of economic events in both variables.

Under this framework, stock returns and annual earnings per share were aggregated over two and five year periods and models 1-4 were re-estimated using two and five year returns over two and five year earnings. Finally in order to examine the impact of both biases on earnings and returns (value-irrelevant noise and time recognition lag) we combined the two previous methodologies by clustering the five-year aggregated variables into 15 portfolios with 7 stocks each and following the same procedure as previous.

\section{Empirical results}

The regression results, of the four models specifications, for the one year period are presented in Table 2. The first column contains the results of the price model (equation 1), the second column includes results from the return model and columns 3 and 4 contain results from the change and deflated models respectively. The evidence indicates that securities returns are significantly associated with the earnings level (Price model) and the earnings level deflated by the previous year's price (Return model). Regarding the changes and the deflated models the only significant results were in 1995 and 2004. On the contrary the price model provided significant results for all the years under investigation while the return model only for the half (1995, 1997, 1999, 2000 and 2004).

\section{INSERT TABLE 2 HERE}

More specifically the most significant ERC in the price model was in 2003 (4.82) and the smallest in 2002 (0.015) which was also insignificant. Moreover, another fact that was documented by Kothari and Zimmerman (1995), is that all models yield significant intercept coefficient which is inconsistent with the theory. It is obvious that 2002 was the only year that did not provide any significant ERC in all four models. This fact can be attributed to the 1999-2000 stock market crash which affected the stock prices movements and the overall stability of the market. In our case the price and return models seem to perform and describe better the return-earnings relation compared to the remaining two specifications. This result is consistent to Kothari and Zimmerman (1995), who found that the price model provides unbiased ERCs but the return model yields ERC which are biased downward, and with other studies that document the ability of price and return models to describe better the aforementioned relation (Bowen, 1981; Olsen, 1985; Landsman, 1986; Barth et.al, 1990 and 1992; Barth, 1991; Harris et.al, 1994).

Additionally, in order to examine the impact of the 1999-2000 stock market crash, we divided the sample into to sub-periods the first from 1994 to 1998 and the second from 1999 to 2004 and estimated again the price and return models (results are not reported here but they can be provided upon request). The price model yields an ERC of 2.72 (the $t$ statistic is 11.27) for the pre-1999 period and an ERC of 0.25 ( $t$ statistic is 1.62) for the post-1999 period, while the return model yield a higher ERC for the pre-1999 period but not statistically significant. Overall we can say that in the Greek case, the price model describes better the return-earnings relation compared to the other three specifications but we must not forget that the four models may suffer from value irrelevant noise and time recognition lag problems.

Consequently, in order to deal with the value irrelevant noise in the earnings variables, we clustered each year's stocks into 15 portfolios with 7 stocks in each one and re-estimated the four models specifications. The mean values of both coefficients and $\mathrm{R}^{2}$ are portrayed in Table 3 . 


\section{INSERT TABLE 3 HERE}

The above results provide evidence for the existence of noise in the earnings variables that causes a downward bias in the estimates of individual stocks. The results concerning the price model are overwhelming. The ERC and $\mathrm{R}^{2}$ have increased significantly for all years under investigation (including 2002). As for the return model, it yields significant ERCs for 8 out of 11 years and of course the overall coefficient of determination has increased considerably compared to Table 1. This result is consistent to Dumontier and Labelle (1998) who also found irrelevant noise in the French accounting earnings and experienced a rather significant improvement in their results after controlling for this bias. Their overall results indicated the superiority of the price and return models over the differenced model.

Also the low informational ability of the price and return models could be attributed to the recognition lag. That is when earnings do not incorporate all the important economic events as fast as prices do. For this reason we increased the returns and earnings measurement intervals in order to include more economic events in the association between earnings and returns. Two and five year returns were summed and regressed over two and five year earnings. The overall results were sensibly improved as the period increases from two to five year measurement window. The two year variables produced ERCs higher than the ERCs of the one year period for all years under consideration. In the pooled sample the ERC is $0.537(\mathrm{t}=3.68$ significant at $\mathrm{a}=1$ per cent) while the ERC for the one year measurement interval is $0.31\left(\mathrm{t}=2.52\right.$ significant at $\mathrm{a}=1$ per cent) and the $\mathrm{R}^{2}$ increased from 0.5 per cent to 1.2 per cent (results are not reported here but it can be provided upon request).

The increase in the earnings response coefficients was even more severe when we increased the measurement window up to five years. Results presented in Table 4 show that the ERC for the pooled sample is 1.35 (5.69 significant at a=1 per cent) and the $\mathrm{R}^{2}$ is up to 4.1 per cent. These results support the main hypothesis that annual earnings do not provide an efficient measure for all the value relevant events captured by the investors and the use of other instrumental variables could improve the return-earnings relation which is based on short period data.

\section{INSERT TABLE 4 HERE}

Finally the last sensitivity test aims at correcting for both biases due to irrelevant noise in earnings and the timeliness of earnings recognition as they were depicted in the last two tables. For this reason we constructed 15 portfolios for each period ( 5 year measurement interval) of 7 stocks each and re-estimated models 1 to 4 . The results, as they are reported in Table 5 show a relative improvement of both ERC and $\mathrm{R}^{2}$.

In the price model column the ERC for the pooled sample increased to 4.65 ( $\mathrm{t}=4.24$ significant at $\mathrm{a}=1$ per cent) from 1.35 an overall increase of 344 per cent. As for the $\mathrm{R}^{2}$ has increased up to 26.6 from 4.1 or alternatively 648 per cent. Regarding the return model the ERC now became significant at $a=5$ per cent $(t=1.94$ from -0.249$)$ and the $R^{2}$ increased from 0.1 per cent to 19.1 per cent.

Summarizing we can say that when temporal and cross-sectional aggregation of data is taken under consideration, it reinforces the returns-earnings relation by diversifying the value irrelevant noise in earnings and the timeliness between the period that a value relevant event occurs and the period when the specific event is incorporated in earnings (Basu, 1997).

\section{INSERT TABLE 5 HERE}

\section{Conclusions, limitations and future research}

The present paper analyses the association between stock returns and earnings in the context of the Hellenic capital market, using four model specifications, the price, return, differenced and deflated models. Data of published earnings and stock prices of 105 companies (all listed in the A.S.E.) for 11 years (1994-2004) were extracted from the Athens Stock Exchange database.

The initial results indicated the increased ability of the price and return models to explain better the aforementioned relationship by providing highly significant earnings response coefficients. The changes and deflated models on the contrary proved to be insufficient compared to the previous two models. These results are consistent to Kothari and Zimmerman (1995), Martikainen et.al (1997) and Dumontier and Labelle (1998).

Additionally, in order to improve the previous results we took under consideration the value irrelevant noise in the earnings variable and recognition lag of value relevant events in earnings. Consequently we re-estimated the previous four models using two refinements. The first deals with the problem of noise in earnings and for that we clustered our sample into 15 portfolios for each year and the second includes the increase of the return and earnings measurement interval (from 1 year to 2 and 5 years) in order to take under consideration more value relevant events.

The final results indicated a high value relevancy in the Hellenic capital market (of course smaller compared to US, France and UK) expressed by the large increase of the ERC and $\mathrm{R}^{2}$ of the price and return models after controlling for the two biases mentioned above. Thus controlling for value irrelevant events and by increasing the variables 
measurement window we achieve to improve the low association of earnings and returns which was documented by many studies in the past.

However, we must mention that our analysis is based on two limitations. The first is that we do not consider the implications of deviations from the random walk property of annual earnings and the second refers to the fact that we did not examined foundational economic reasons that grounds the previously mentioned relation, as well as alternative econometric techniques that could improve the final result. A fruitful path for future research is to examine the effect of losses (negative earnings) in the earnings-returns relation and the inclusion of leading periods in earnings and returns as measures of increasing the earnings response coefficients and the explanatory power of the models.

\section{Acknowledgements}

We wish to thank Professor Costas Syriopoulos and Dr. Evangelos Koumanakos from the University of Patras, for providing us all the necessary data for the completion of this paper, participants on the $1^{\text {st }}$ International Conference in Accounting and Finance of the University of Macedonia-Thessaloniki and the editor Amy King as well as two anonymous reviewers for useful comments and suggestions. Their contribution is highly acknowledged. Needless to say that the responsibility for any errors and omissions rests entirely with us.

\section{References}

Alford A., Jones J., Leftwich R. and Zmijewski M. (1993). The relative informativeness of accounting disclosures in different countries. Journal of Accounting Research, 31 (Suppl.), 183-223.

Ball, R. and Brown, P. (1968). An empirical evaluation of accounting income numbers, Journal of Accounting Research, 6, 159-78.

Barth, Mary E, William H. Beaver, and Mark A. Wolfson, (1990). Components of bank earnings and the structure of bank share prices. Financial Analysts Journal, 46 May/June, 53-60.

Barth, Mary E., (1991). Relative measarement errors among alternative pension asset and liability measures. The Accounting Review, 66, 433-463.

Barth, Mary E., William H. Beaver, avid Wayne R. Landsman, (1992). The market valuation implications of net periodic pension cost components. Journal of Accounting and Economics, 15, 2-62.

Basu, Sudipta, (1997). The conservatism principle and the asymmetric timeliness of earnings. Journal of Accounting and Economics, 24, 3-37.

Beaver, W. H., R. Lambert, and D. Morse (1980). The information content of security prices. Journal of Accounting and Economics, 2, 3-28.

Beaver, William H., (1989). Financial accounting: An accounting revolution. Prentice-Hall, Engle-wood Cliffs, N J.

Board, J. and Day, J. (1989). The information content of cash flow figures. Accounting and Business Research, 20, 3-11.

Bowen R. M. (1981). Valuation of earnings components in the electric utility industry. The Accounting Review, 56, 1-22.

Christie A. A., (1987). On cross-sectional analysis in accounting research. Journal of Accounting and Economics, 9, 231-258.

Collins, D. W., S.P. Kothari, J. Shanken, and R. G. Sloan, (1994). Lack of timeliness versus noise as explanations for low contemporaneous return-earnings association. Journal of Accounting and Economics, 18, 289-324.

Dumontier P. and Labelle R. (1998). Accounting earnings and firm valuation: the French case. The European Accounting Review, 7 (2), 163-183.

Gonedes N. J. and N. Dopuch, (1974). Capital market equilibrium, information production, and selecting accounting techniques: Theoretical framework and review of empirical work. Journal of Accounting Research, 12 (Suppl.), 48-130.

Harris, T. S. M. Lang. and H. P. Moiler, (1994). The value-relevance of German accounting measures: An empirical analysis. Journal of Accounting Research, 24, 187-209.

Kormendi R. and R. C. Lipe, (1987). Earnings innovations, earnings persistence and stock returns. Journal of Business, 60, 323-345.

Kothari, S. P., Zimmerman, J. L (1995). Price and return models. Journal of Accounting and Economics, 20, 155-192.

Landsman, W. R., (1986). An empirical investigation of pension fund property rights. The Accounting Review, 61, 662-691. 
Lev B. and J. A. Ohlson, (1982). Market based empirical research in accounting: A review, interpretations, and extensions. Journal of Accounting Research, 20 (Suppl.), 249-322.

Lev B. (1989). On the usefulness of earnings: Lessons and directions from two decades of empirical research. Journal of Accounting Research, 27(Suppl.), 153-192.

Martikainen T. and Perttunen J. (1991). Return intervals, systematic risk and firm size: Evidence form a thin security market. Economics Letters, 36, 311-315.

Martikainen, T., Kallunki, J. and Perttunen, J. (1997). Finnish earnings response coefficients: the information content of losses. The European Accounting Review, 6 (1), 69-81.

Ohlson, J. A., (1991). The theory and value of earnings and an introduction to the Ball-Brown analysis. Contemporary Accounting Research, 8, 1-19.

Ohlson, J. A. and P. K. Shroff, (1992). Changes versus levels in earnings as explanatory variables for returns: Some theoretical considerations. Journal of Accounting Research, 30, 210-226.

Olsen, C., (1985). Valuation implication of SFAS no. 33 data for electric utility investors. Journal of Accounting Research, 23 (Suppl.), 28-47.

Pritchard N. J. (2002). The Relationship between Accounting Numbers and Returns in the Baltic Stock Markets. Discussion Paper 2002/06/May 2002, Heriot-Watt University.

Ramakrishnan, R. and Thomas, J., (1998). Valuation of permanent, transitory and price-irrelevant components of reported earnings. Journal of Accounting Auditing and Finance, 13 (3), 301-336.

Raonic I., S. McLeay and I. Asimakopoulos (2004). The Timeliness of Income Recognition by Interlisted European Companies: An Analysis of Institutional and Market Complexity. Journal of Business Finance and Accounting, 31 (1-2), 115-148.

Vafeas N., Trigeorgis L. and Georgiou X. (1998). The usefulness of earnings in explaining stock returns in an emerging market: the case of Cyprus. The European Accounting Review, 7 (1), 105-124.

Watts R. L. and J. L. Zimmerman (1986). Positive accounting theory. Prentice-Hall, Engle-wood Cliffs, N J.

White H. (1980). A heteroscedasticity consistent covariance matrix estimator and a direct test for heteroscedasticity. Econometrica, 48, 817-838.

Table 1. Descriptive statistics of earnings and price variables used in the valuation of the price, return and differenced price models specifications. Sample consists of annual data from 1994-2004.

\begin{tabular}{|cccccc|}
\hline Variable & Mean & St.Deviation & Minimum & Median & Maximum \\
\hline $\mathrm{EPS}_{\mathrm{t}}$ & 0.37 & 2.72 & -9.39 & 0.17 & 87.8 \\
$\mathrm{P}_{\mathrm{t}}$ & 6.26 & $1 ., 3$ & 0.08 & 2.83 & 128.7 \\
$\mathrm{EPS}_{\mathrm{t}} / \mathrm{P}_{\mathrm{t}-1}$ & 0.11 & 0.96 & -13.2 & 0.045 & 24.5 \\
$\mathrm{P}_{\mathrm{t}} / \mathrm{P}_{\mathrm{t}-1}$ & 1.82 & 3.77 & 0.05 & 0.928 & 51.42 \\
$\Delta \mathrm{EPS}_{\mathrm{t}} / \mathrm{P}_{\mathrm{t}-1}$ & -0.022 & 1.73 & -47.4 & -0.0024 & 24.52 \\
$\Delta \mathrm{P}_{\mathrm{t}} / \mathrm{P}_{\mathrm{t}-1}$ & 0.76 & 3.84 & -18.62 & -0.072 & 50.42 \\
\hline
\end{tabular}

Sample: The overall sample consists of 105 firms with full earnings and price data for 1994-2004. $\mathrm{EPS}_{\mathrm{t}}$ is annual earnings per share excluding taxes, extraordinary items and discontinued operations. Price variables are measured over the fiscal year. Only firms with December fiscal year-end are included. Earnings and prices are adjusted for stock splits and stock dividends in order to obtain the differenced variables. 

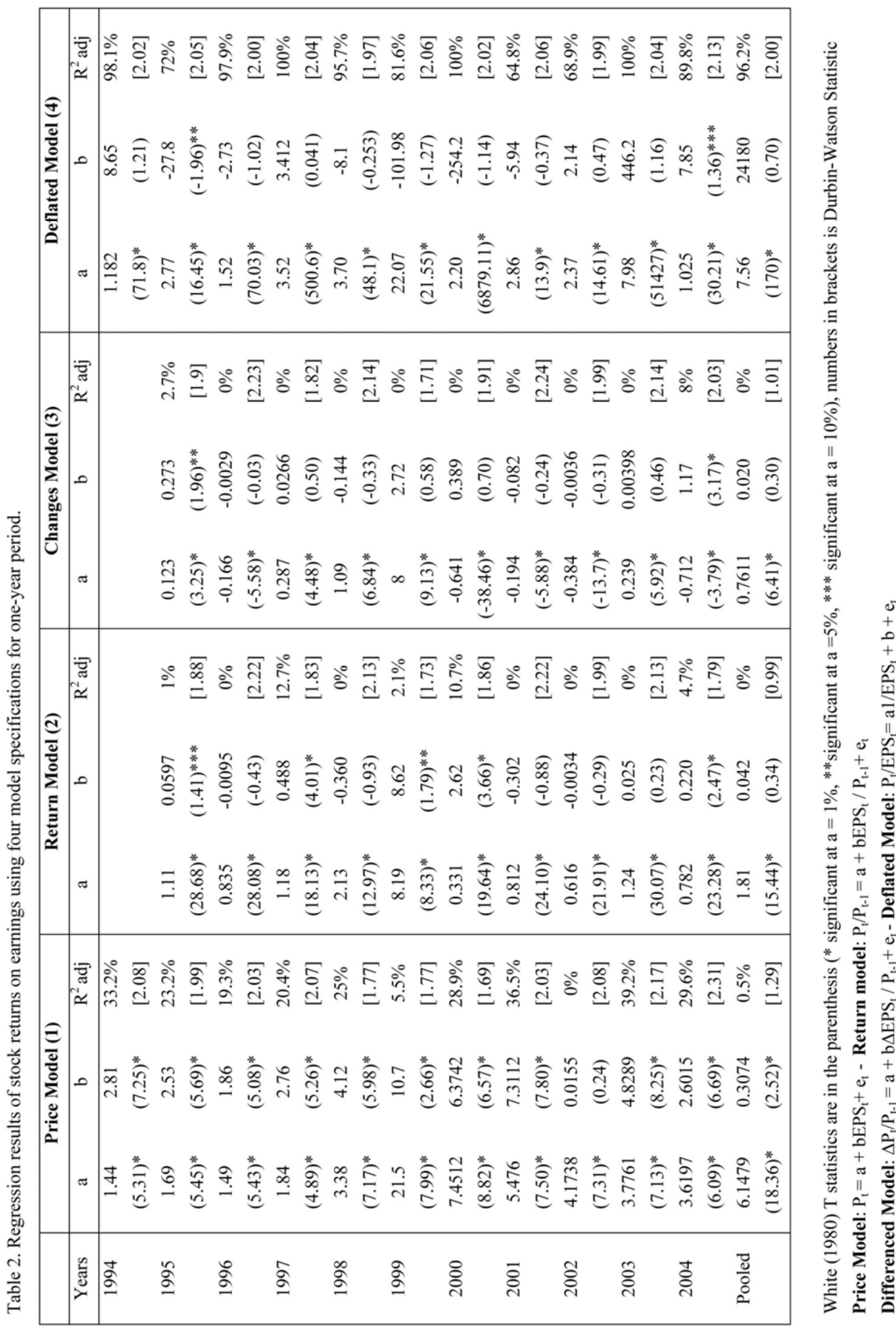


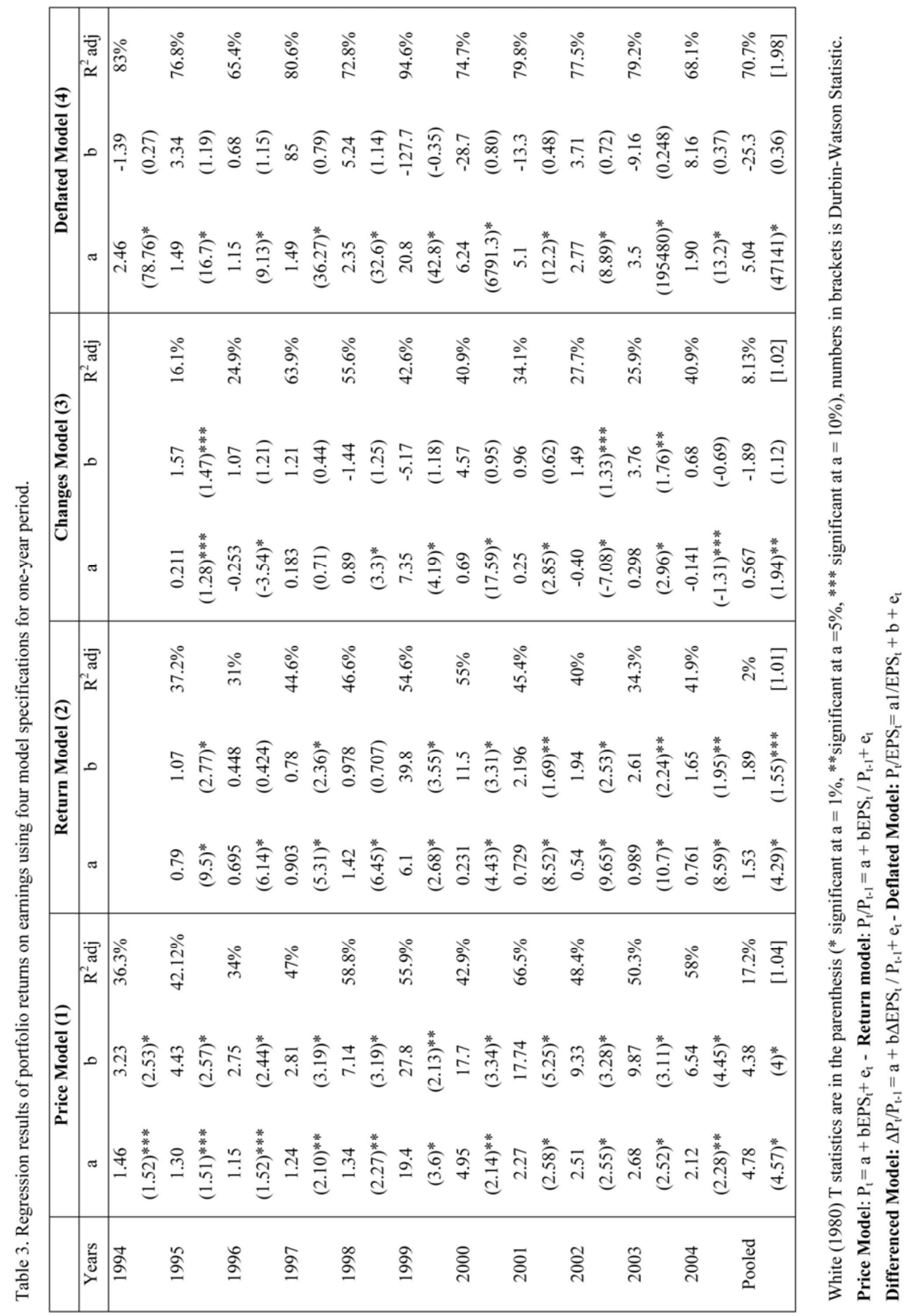




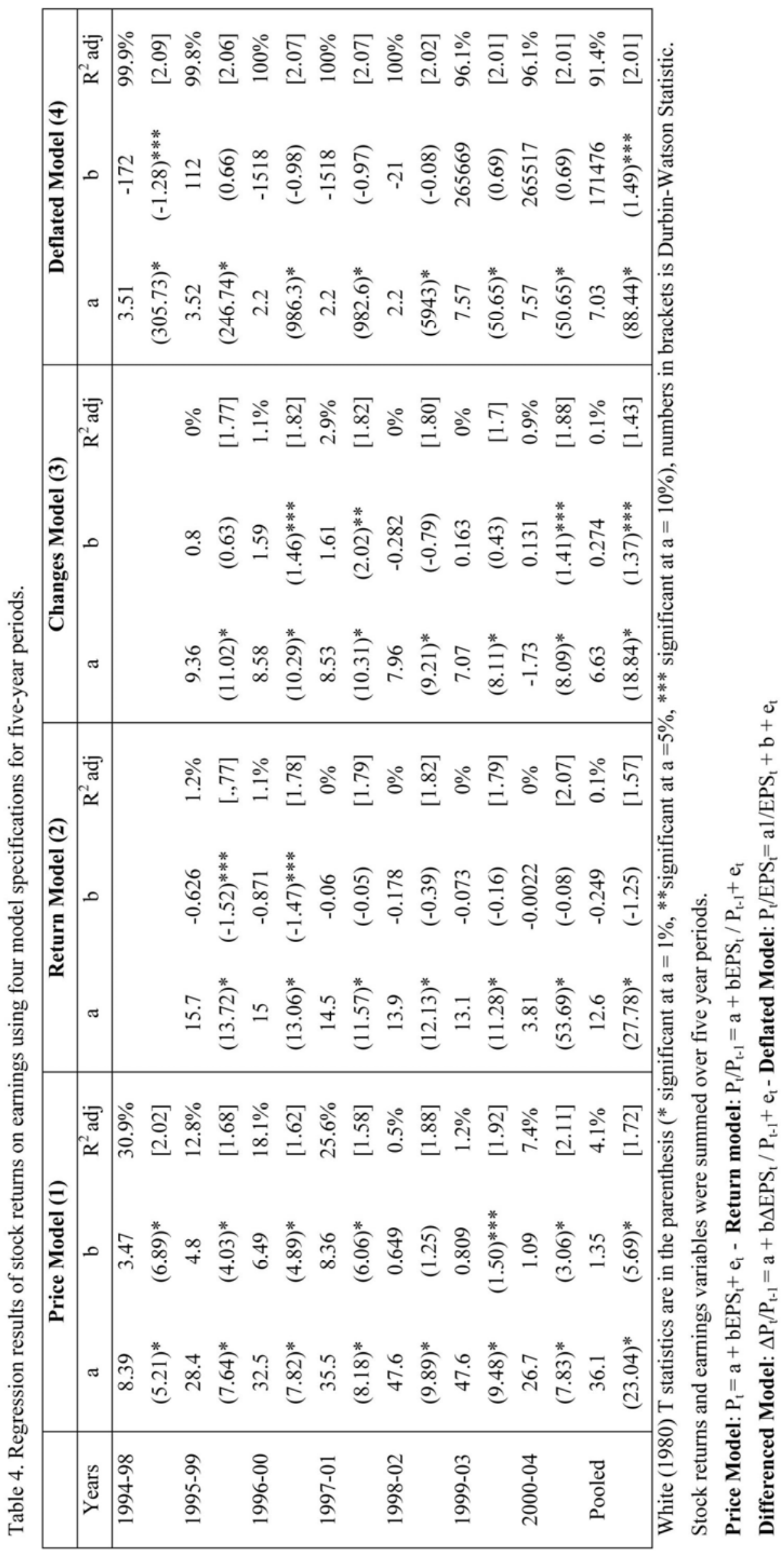




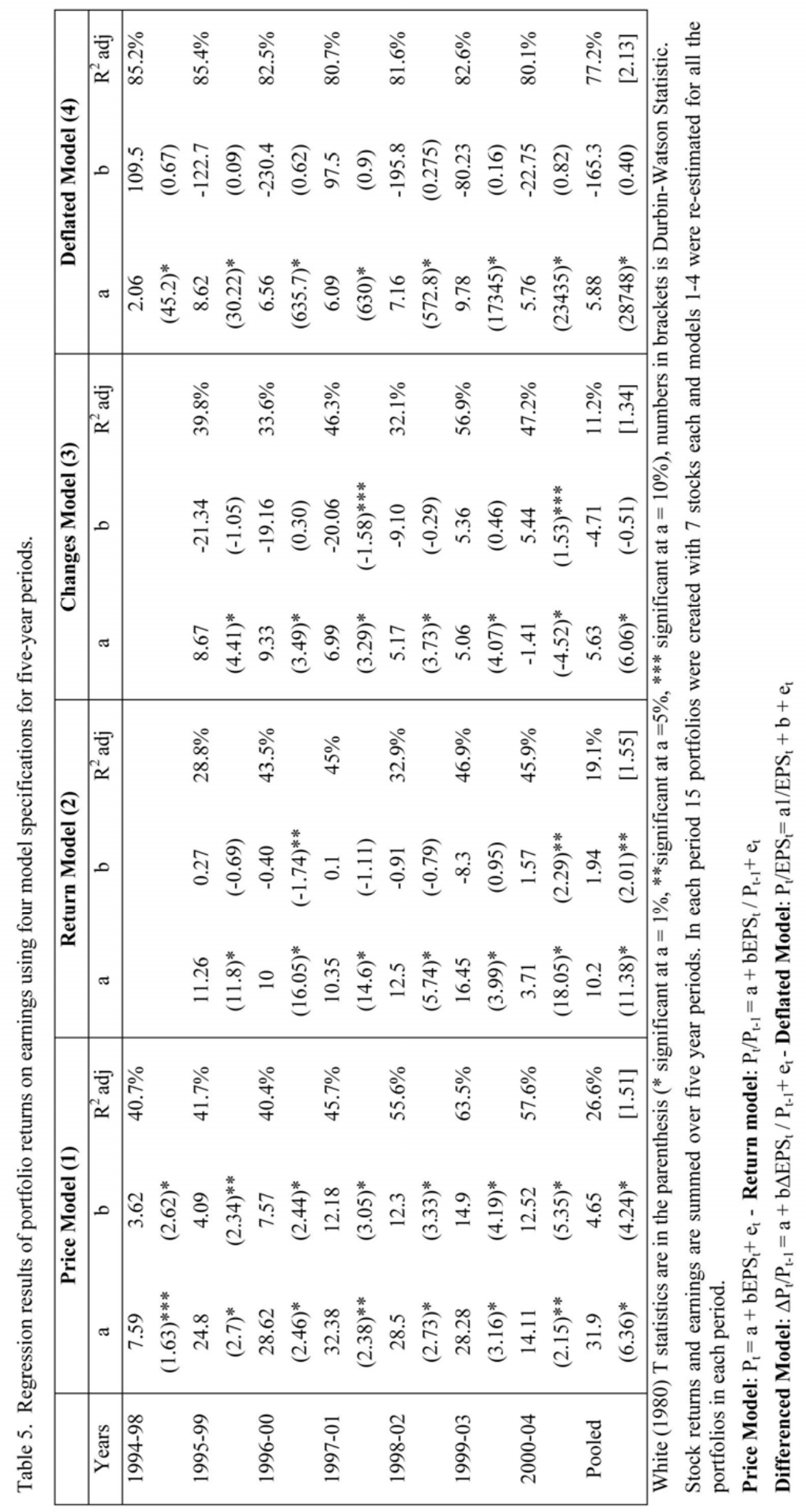

